\title{
Rose Hip Powder That Contains the Natural Amount of Shells and Seeds Alleviates Pain in Osteoarthritis of the Dominant Hand-A Randomized, Double-Blind, Placebo-Controlled, Cross-Over Clinical Trial
}

\section{Kaj Winther, Joan Campbell-Tofte, Peter Hansen}

Department of Clinical Biochemistry, Coordinating Research Unit, Frederiksberg University Hospital, Frederiksberg, Denmark. Email: Kaj.Flemming.Winther.Hansen@regionh.dk

Received May $23^{\text {rd }}, 2013$; revised June $24^{\text {th }}, 2013$; accepted July $2^{\text {nd }}, 2013$

Copyright (C) 2013 Kaj Winther et al. This is an open access article distributed under the Creative Commons Attribution License, which permits unrestricted use, distribution, and reproduction in any medium, provided the original work is properly cited.

\begin{abstract}
Aim: A standardized preparation of seeds and shells of selected sub-species of Rosa canina L, trade name Hyben Vital ${ }^{\circledR}$, reduces discomfort from osteoarthritis of the knee and hip. This study aims to investigate the impact of the same rosehip powder (RHP) on discomfort and the consumption of rescue medication, in patients with osteoarthritis of the hand. Methods: The double blind, placebo-controlled, crossover trial included 30 patients with osteoarthritis of the dominant hand. Patients were randomly allocated to treatment with either five gram encapsulated RHP or placebo, for three months (Phase 1), after which they switched to the corresponding treatment for a further three months period (Phase 2). Before entering the study, after 3 weeks and following three months of each of the study phases, scores for pain, stiffness and general feeling of discomfort were evaluated using a 10 step categorical scale, focusing on 16 different daily activities of the hand. The consumption of rescue medication was also calculated at the beginning and at the end of each study phase. Data are based on the intention to treat. Results: At the end of Phase 1, 90\% of patients in the group receiving RHP first (group A), showed a reduction in pain, as compared to $36 \%$ in the group B initially given placebo (p $<0.029)$. In line with this observation, stiffness and the general feeling of discomfort from the disease declined during RHP treatment $(\mathrm{p}<0.032)$. In group A, symptom reduction was still indicated by the study subjects 3 weeks after the switch to placebo. The consumption of rescue medication such as paracetamol, codeine and tramadol also declined significantly in group A when compared to group B $(\mathrm{p}<0.013)$. Conclusion: The present data suggest that administration of RHP, containing seeds and shells can reduce symptoms of osteoarthritis of the hand and consumption of rescue medication.
\end{abstract}

Keywords: Clinical Studies of Osteoarthritis; Musculoskeletal and Joint Diseases; Chronic Pain and Discomfort; Rosa canina; Rose Hip; Hand; Osteoarthritis; Traditional Medicine; Herbal Remedies

\section{Introduction}

In addition to their culinary uses, roses were also valued for their medicinal properties all over medieval Europe. In the Complete German Commission E monographs of Therapeutic Guide to Herbal Medicines, Blumenthal et al. [1] lists rose hip with or without fruits (achenes) for the treatment of colds, as a laxative, diuretic, anti-gout and anti-rheumatism. Indeed, rose hip powder for addition to breakfast cereals or packaged in capsules/tablets is a common inventory in Health Food stores all over Europe.

Based on evidence for its ethnopharmacological application, a standardized powder $\left(\right.$ Hyben Vital $^{\circledR}$ ) based on selected subspecies of Rosa canina and prepared in Langeland, Denmark, under very standardized circumstances as described by Rein et al., [2] containing an equal amount of seeds and shells, has been investigated and shown to be useful for treating patients suffering from osteoarthritis (OA) of the knee and/or hip [2-4] and from rheumatoid arthritis [5]. OA is essentially a disease of wear and tear of articular cartilage, due to frictional movements within the joint. In general, about $90 \%$ of the population shows the earliest X-ray criteria of OA by the age of 40 . The hand is technically not "a joint" but a marvelous piece of evolutionary bio-engineering that 
involves many joints-interphalangeal, metacarpo-phalangeal, intermetacarpal, and carpal-metacarpal, the last including the all-important basal joint of the thumb, with its remarkable mobility that allows us to appose the tip of the thumb to the tips of the other four fingers and so to grasp at and lay hold of objects. The hand as a whole can perform tasks as different as playing the piano, where finger dexterity and light touch are required for quite long periods, to the momentary violent effort of the weightlifter or pole-vaulter, who need a secure, five-finger wraparound grip, plus braced wrist joints. None of these joints are immune from OA.

$\mathrm{OA}$ is triggered by inflammatory reactions set off by cartilage destruction. The inflammatory polymorphonuclear leukocytes are known to be causally involved in inflammation, pain and the resulting tissue damage caused by the release of proteolytic and hydrophilic enzymes and reactive oxygen radicals derived from cells at the joints and surrounding tissues [6]. The non-surgical therapy for OA mainly involves alleviation of the symptoms of pain and stiffness and the reduction of inflammation. Acetylsalicylic acid and a range of NSAIDs including ibuprophen, indomethacin and naproxen, as well as glucocorticoids, have been used for the treatment of symptoms of arthritis. These drugs have a variety of toxic and unwanted effects, including interference with haemostasis, gastric erosion and adverse effects on the liver and kidneys [7-9]. Selective inhibitors of the proinflammatory cyclooxygenase-2 (Cox2) have recently shown promising analgesic and anti-inflammatory properties, without the side effects mentioned above. However, the Cox2 inhibitors are very expensive and a negative effect on the circulatory system cannot be excluded [10-12]. Moreover, paracetamol or acetaminophen was shown to worsen the risk of upper gastrointestinal complications [13]. There is, therefore a need for safer and preferably, low-cost remedies for the long-term treatment of OA. The optimal treatment should be chondroprotective or even chondroregenerative, and not simply a painkiller that alleviates disease symptoms without curing the disease.

We have earlier shown that the anti-inflammatory effect of the standardized rose hip powder (RHP), which contains the natural amounts of the shell and seeds, is not related to the well-known high vitamin $\mathrm{C}$ content of the preparation $[14,15]$. In controlled trials, pain was diminished after a few weeks of treatment with the powder in several patients with OA of the hip and knee [2-4]. A galactolipid named GOPO with anti-inflammatory and anti oxidative properties was isolated and found to be very high in the present RHP [16]. In addition, GOPO was shown to be chondroprotective and regenerative when tested on human chondrocytes [17]. As OA of the hand has a limiting influence on several daily activities, we found it of relevance, to examine whether the RHP also reduces symptoms of osteoarthritis there.

\section{Methods}

\subsection{Patients}

This work is a sub study of a larger study on OA of different joints which has previously been published elsewhere [2]. The data especially focusing on OA of the dominant hand was not published then. The study was performed according to good clinical practice, in accordance with the Declaration of Helsinki and was approved by the local Ethical Committee. The participants in the main study were 125 Caucasian outpatients who were all enrolled through advertisements in local newspapers. Forty patients reported suffering from OA of the hand with mild to moderate severity. Of these, thirty patients met the criteria for OA of the dominant hand, as outlined by the American College of Rheumatology [18]. For example, all of them tested positive when given simple tests for the detection of manual handicap, especially the grip $[19,20]$. All volunteers gave their written informed consent and had been diagnosed with OA for at least 12 months previously.

Patients with liver or kidney disease and those with known allergies or a history of drug or alcohol abuse were excluded. Other exclusion criteria included patients diagnosed with cancer, fibromyalgia, gout, serious cardiovascular disease, and asthma requiring treatment with steroids. Likewise, patients already prescribed intra-articular hyaluronate, glucosamine sulphate and immunosuppressive drugs such as gold or penicillamine or injections of glucocorticoids within the 6 weeks prior to starting the study, or those found to be unable to cooperate after the first evaluations were excluded.

\subsection{Trial Design}

The trial was of a randomized, double-blinded, placebocontrolled, crossover design, as diagrammatized in Figure 1 and outlined by Rein et al. [2]. Thirty of the patients, with OA of the dominant hand, wanted to participate in the present sub study. After a run-in period of 14 days, the participants were randomly allocated to either group A or group B, and treated with five capsules containing 0.5 gram of either RHP or placebo, administered twice daily for three months. Following this period that constituted the first phase of the study, the patients were immediately switched to the alternative medication and entered into Phase 2. Thus, group A (active treatment first, then placebo) included 16 randomized patients, while group B (placebo first, then RHP) was made up of 14 patients. 


\section{(14 days $\quad$ Phase 1:3 months $\quad$ Phase 2:3 months
run-in)}

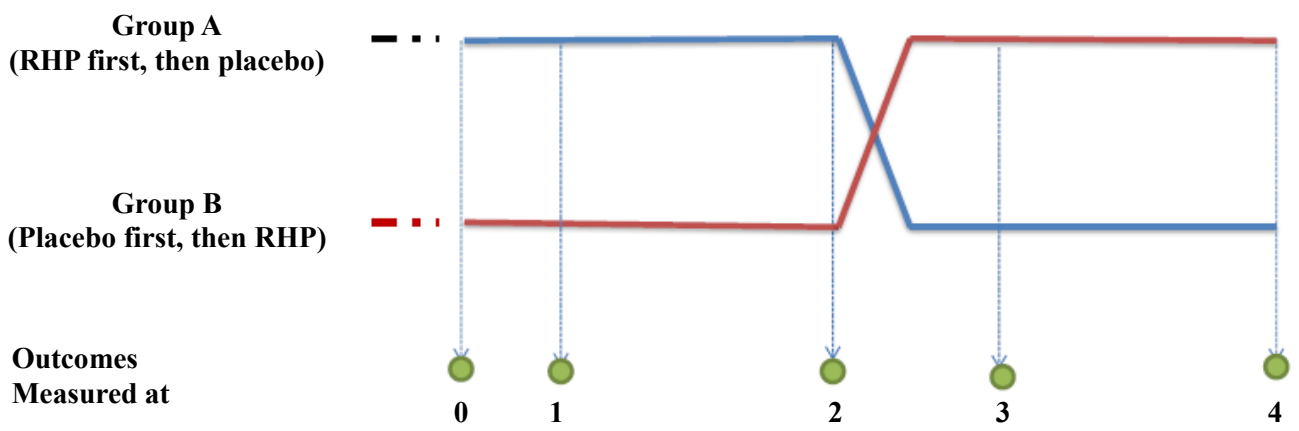

Figure 1. Study design for assessing the efficacy of rose hip powder and placebo on osteoarthritis of the hand. Outcomes 0 , 1, 2, 3 and 4 correspond to data of disease symptom assessments taken from study participants before entry into the study, after the first 3 weeks in Phase 1, after 3 months in Phase 1, after the first 3 weeks in Phase 2 and following the 3 months of Phase 2, respectively.

Before and at the end of each of the two study phases, blood samples were collected for determination of C-reactive protein levels and the patients were evaluated for their pain and stiffness and overall feeling of discomfort from their disease (osteoarthritis of the dominant hand). In addition the consumption of all types of rescue medication was calculated each day. Later, the consumption of rescue medication during the first 14 days of the treatment period was compared to the consumption of the last fourteen days of each study phase.

\subsection{Preparation and Composition of the Investigational Medicines}

The RHP used in this study is prepared from selected subspecies of rose plant by Hyben Vital, Langeland, Denmark. The preparation contains all the seeds and the entire shell of the rose-hip berries, turned into a powder, and is on the market in several European countries and in Australia. No minerals or vitamins are added to the powder and nothing, but the small hairs of the seeds are removed from the fruit, using a standard operating procedure. Briefly, a patented, long lasting and drying procedure that never exceeds $40^{\circ} \mathrm{C}$ is used. As stated by Rein et al. [2], $100 \mathrm{~g}$ of RHP contains at least $500 \mathrm{mg}$ Vitamin $\mathrm{C}, 5.8 \mathrm{~g}$ pectin, $5.8 \mathrm{mg} \beta$-carotene, $50 \mathrm{mg} \beta$-sitosterol, $0.2 \mathrm{mg}$ folic acid, $4.6 \mathrm{mg}$ Vitamin E, $170 \mathrm{mg} \mathrm{Mg}, 1 \mathrm{mg}$ $\mathrm{Zn}$ and $10.9 \mu \mathrm{g} \mathrm{Cu}$. Moreover, the seeds of the particular species of rose plants used in this study are particularly rich in cytokines, unsaturated fatty acids, fibres and proteins. Placebo consisting of a powder made to similar colour, taste and odour was also supplied by the same company. Both investigational medicines were encapsulated in identical white capsules, each containing $0.5 \mathrm{~g}$ RHP or placebo.

\subsection{Methods of Assessing Clinical Effects}

The primary efficacy parameter was reduction in joint pain of the dominant hand evaluated as a mean of 16 different tests, using a 10-step categorical scale, ranging from 0 (no pain) to 10 (almost unbearable pain). Testing was performed initially before entry into the trial, after 3 weeks and again after 3 months of treatment with either RHP or placebo, depending on whether the participant was in group A or group B (Figure 1). After three months, i.e. at the end of Phase 1 of the study period, the participants were switched to the alternative treatment, and again tested after 3 weeks and after 3 months. The scores registered at the testing points correspond to outcomes 0 (before-entry-into-study-measurements), and outcomes 1 to 4 , for scores taken at the subsequent 4 assessment points indicated in Figure 1. The 16 different tests were focused on the following activities: 1) pain when awakening in the morning and slowly opening and closing the hand, 2) holding heavy things in the hand, 3) pouring from a water jug, 4) holding a cup and using a knife and fork, 5) wringing out a dishcloth, 6) peeling potatoes, 7) unscrewing a bottle top, 8) getting a pill out of a blister pack, 9) opening a milk carton, 10) tying shoelaces, 11) managing a toothbrush, 12) writing with a pen or pencil, 13) holding a book in the hand for reading, 14) using garden tools, 15) using a corkscrew or tinopener and 16) holding or picking up small items from a table. With each activity, the higher the score the greater was the pain. The secondary efficacy parameters were changes in joint stiffness (as determined by patients during the assessment of pain), overall feeling of discomfort caused by the disease using one simple categorical scale and consumption of rescue medication. Blood levels of the $\mathrm{C}$-reactive protein were determined using standard ELISA tests. 


\subsection{Rescue Medication}

Each type of rescue medication was daily noted in a diary. All patients taking NSAIDs regularly on prescription from their general practitioners were advised to continue with their treatments throughout the study. After three weeks into Phase 1 and Phase 2, we recommended that the patients reduce their consumption of other types of concomitant pain-relieving medications; if at all this was possible. At the end of each 3-months study phase, we calculated the consumption of the various types of rescue medication. We simplified the calculation of rescue medication by transformation of rescue medication (Codeine and Tramadol) into paracetamol equivalents as devised by the Danish Health Authorities ("Lægemid-delkataloget”, 2002). Paracetamol tablets used in this trial were invariably $500 \mathrm{mg} /$ tablet.

\subsection{Statistical Evaluation}

Statistical evaluation was based on the intention to treat (ITT). Wilcoxon's test for matched pairs was applied when evaluating the study as a simple crossover trial and in comparing effects occurring within the same group of patients. The Mann-Whitney test was applied to comparison of groups A and B after 3 and 6 months treatment, while Fisher's test was used for simple evaluation on a yes/no basis. Unless otherwise stated, all data are presented as mean $\pm \mathrm{SD}$. Any $\mathrm{p}$ value equal to or less than 0.05 was regarded as statistically significant.

\section{Results}

\subsection{Description of the Study Participants}

Thirty OA patients (4 men and 26 women) signed up for the present sub study. All study participants reported on their rescue and additional medications. During the course of the study, 24 patients (10 patients in group A and 14 patients group B) returned adequate assessment questionnaires for pain, stiffness and general wellbeing. The baseline clinical characteristics of the study subjects are detailed in Table 1. The groups were matched in their demographic data, in the severity of osteoarthritis and function of the dominant hand, as well as in their consumption of rescue medicine.

\subsection{Reduction in Pain from Osteoarthritis of the Dominant Hand}

When the active and placebo treatment data are pooled from the A and B groups and the average of the 16 individual activity scores are considered as index of effect in each person, there was a borderline significant lessening of pain with active treatment as compared to placebo,
Table 1. Baseline clinical characteristics of the study subjects.

\begin{tabular}{cccc}
\hline Characteristics & $\begin{array}{c}\text { Group A } \\
\text { (Treatment/ } \\
\text { Placebo) }\end{array}$ & $\begin{array}{c}\text { Group B } \\
\text { (Placebo/ } \\
\text { Treatment) }\end{array}$ & p value $^{\mathbf{a}}$ \\
\hline Women & 14 & 12 & 1.0 \\
Men & 2 & 2 & 1.0 \\
Age, years & $61.2 \pm 13.3$ & $57.3 \pm 11.8$ & 0.6 \\
Body weight & $64 \pm 8.4$ & $69.3 \pm 15.7$ & 0.9 \\
BMI & $23.9 \pm 3.4$ & $25.4 \pm 3.7$ & 0.8 \\
NSAID & 4 & 5 & 0.8 \\
Paracetamol & 8 & 6 & 1.0 \\
Codeine & 1 & 1 & 1.0 \\
Tramadol & 0 & 3 & 0.2 \\
Pain scores & $5.1 \pm 2.2$ & $5.2 \pm 2.2$ & 0.9 \\
Stiffness scores & $5.0 \pm 1.6$ & $4.8 \pm 2.3$ & 0.7 \\
PGAD & $5.7 \pm 3.0$ & $5.4 \pm 3.5$ & 0.8 \\
\hline
\end{tabular}

${ }^{\mathrm{a}}$ Level of significance is calculated using Mann-Whitney; 'PGAD; patients' global assessment of disease severity.

when tested after three months ( $p<0.089)$, Table 2. Furthermore, when the patients were evaluated on the basis of positive responder (defined as patients who reduced their pain score); or non-responder (defined as patients who did not reduce their pain score), $90 \%$ in the actively treated patients (group A) reported a reduction in pain. This should be compared to $36 \%$ in the corresponding placebo group (group B) $(p<0.029)$, when evaluating participant response after the first 3 months of the study (i.e. at the end of Phase 1). This reduction in pain experienced by the study subjects administered RHP in Phase 1, was still expressed 3 weeks after they had switched to treatment with placebo in Phase 2 (Table 3). When the 16 different activities were evaluated separately, the activity showing the most pronounced decline in pain was handwriting a letter, as Active treatment resulted in a $20 \%$ significant $(\mathrm{p}<0.030)$ reduction in pain after three weeks and a $26 \%$ reduction after 3 month and at the end of Phase $1(p<0.014)$. By comparison, no change was observed with placebo, where comparing the corresponding groups resulted in a $\mathrm{p}$ value of 0.077 . Other "high scorers" in pain reduction were using a corkscrew and pressing tablets out of a blister package. With these activities, the reduction in pain during active treatment was less- $16 \%$ and $18 \%$, respectively, but when compared to placebo, there was a reduction in pain that was statistically significant in favour of active treatment $(\mathrm{p}<0.048$ and $\mathrm{p}<0.003)$ respectively, using MannWhitney. 
Table 2. Pain, stiffness, patients assessment of disease severity $($ PGAD) and CRP levels in study participants $(\mathrm{n}=24)$. Data given (mean \pm SD) are pooled data for overall response to active and placebo treatments in the $A$ group (active first, then placebo) and B group (placebo first, then active treatment). Delta1 $(\Delta 1)$ values correspond to Initial assessment values for disease symptoms minus the 3 weeks assessment values. Delta2 $(\Delta 2)$ values correspond to Initial assessment values minus 3 months assessment values.

\begin{tabular}{ccccccccccccc}
\hline & \multicolumn{1}{c}{ ACTIVE } & \multicolumn{4}{c}{ PLACEBO } & \multicolumn{4}{c}{$\begin{array}{c}\text { Comparing Active } \\
\text { vs. Placebo }\end{array}$} \\
\hline Scores & Initial values & 3 weeks & $\Delta \mathbf{1}$ & 3 months & $\Delta \mathbf{2}$ & 3 weeks & $\Delta \mathbf{1}$ & 3 months & $\Delta \mathbf{2}$ & 3 weeks 3 months \\
Pain & $5.1 \pm 2.2$ & $4.7 \pm 2.3$ & $0.5 \pm 1.2(1)$ & $4.4 \pm 2.5$ & $0.7 \pm 1.7(2)$ & $4.6 \pm 2.3$ & $0.8 \pm 1.4$ & $5.0 \pm 2.6$ & $0.2 \pm 1.9$ & 0.956 & 0.189 \\
Stiffness & $4.9 \pm 2.0$ & $4.4 \pm 2.1$ & $0.5 \pm 1.5(3)$ & $4.2 \pm 2.3$ & $0.6 \pm 2.0$ & $4.5 \pm 2.1$ & $0.4 \pm 1.2$ & $4.6 \pm 2.5$ & $0.2 \pm 1.9$ & 0.411 & 0.134 \\
PGAD & $5.5 \pm 3.3$ & $5.1 \pm 3.0$ & $0.4 \pm 2.6$ & $4.3 \pm 2.5$ & $1.2 \pm 2.6(1)$ & $4.6 \pm 3.2$ & $0.9 \pm 1.6(5)$ & $5.3 \pm 3.0$ & $0.2 \pm 2.9$ & 0.449 & 0.091 \\
CRP (6) $\mathrm{mg} \cdot \mathrm{l}^{-1}$ & $10.1 \pm 7.7$ & $\mathrm{ND}$ & - & $6.3 \pm 4.2$ & $3.8 \pm 5.2(1)$ & $\mathrm{ND}$ & & $7.3 \pm 4.0$ & $2.8 \pm 4.6$ & & \\
\hline
\end{tabular}

(1) to (5) and (7) indicate significant differences in delta values of within-group differences. $(1)=\mathrm{p}<0.026 ;(2)=\mathrm{p}<0.038 ;(3)=\mathrm{p}<0.017 ;(4)=\mathrm{p}<0.015 ;(5)$ $=\mathrm{p}<0.008 ;(7)=\mathrm{p}<0.047 ;(6)$ For CRP, $\mathrm{n}=8 ; \mathrm{ND}=$ not determined

Table 3. Changes in pain, stiffness and PGAD in patients with osteoarthritis of the dominant hand in data from the A and B groups, respectively. Delta1 values correspond to Initial assessment values for disease symptoms minus the assessment values taken after 3 weeks into Phase 1 of the study period; Delta2 values correspond to Initial assessment values minus the 3 months assessment values at the end of Phase 1; Delta3 measures correspond to Initial assessment values minus 3 weeks assessment values in the beginning of Phase 2 of the study period; while Delta4 values correspond to Initial assessment values minus the 3 month assessment values taken at the end of Phase 2.

\begin{tabular}{|c|c|c|c|c|c|c|c|c|c|}
\hline \multicolumn{10}{|c|}{ Group A (Active treatment first, then placebo; $\mathrm{n}=10$ ) } \\
\hline Score(s) & $\begin{array}{c}\text { Start- } \\
\text { Outcome } 0\end{array}$ & $\begin{array}{l}3 \text { weeks- } \\
\text { Outcome } 1\end{array}$ & Delta1 & $\begin{array}{l}3 \text { months- } \\
\text { Outcome } 2\end{array}$ & Delta2 & $\begin{array}{c}3 \text { weeks- } \\
\text { Outcome } 3\end{array}$ & Delta3 & $\begin{array}{l}3 \text { months- } \\
\text { Outcome } 4\end{array}$ & Delta4 \\
\hline Pain & $5.1 \pm 2.2$ & $4.8 \pm 2.2$ & $0.3 \pm 1.1$ & $3.9 \pm 2.2$ & $1.2 \pm 1.6(\mathbf{1})$ & $4.1 \pm 1.9$ & $1.1 \pm 1.4(2)$ & $4.4 \pm 2.1$ & $0.7 \pm 1.7$ \\
\hline Stiffness & $5.0 \pm 1.6$ & $4.6 \pm 1.6$ & $0.4 \pm 0.3(3)$ & $4.1 \pm 2.1$ & $0.9 \pm 1.7$ & $4.4 \pm 1.9$ & $0.6 \pm 1.2$ & $4.4 \pm 2.3$ & $0.6 \pm 1.2$ \\
\hline PGAD $^{*}$ & $5.7 \pm 3.0$ & $5.1 \pm 2.8$ & $0.6 \pm 1.9$ & $3.8 \pm 2.4$ & $1.9 \pm 2.1(4)$ & $4.0 \pm 2.5$ & $1.7 \pm 1.7(5)$ & $39 \pm 2.9$ & $1.8 \pm 2.3(6)$ \\
\hline \multicolumn{10}{|c|}{ Group B (Placebo first, then active treatment; $n=14$ ) } \\
\hline Pain & $5.2 \pm 2.2$ & $5.0 \pm 2.6$ & $0.1 \pm 1.3$ & $5.4 \pm 2.9$ & $-0.2 \pm 2.0(\mathbf{a})$ & $4.6 \pm 2.5$ & $0.6 \pm 1.3(7)$ & $4.8 \pm 2.7$ & $0.4 \pm 1.7$ \\
\hline $\begin{array}{c}\text { Stiffness } \\
(n=13)\end{array}$ & $4.8 \pm 2.3$ & $4.5 \pm 2.3$ & $0.2 \pm 1.2(\mathbf{b})$ & $4.8 \pm 2.7$ & $0.0 \pm 2.1$ & $4.2 \pm 2.5$ & $4.2 \pm 2.5$ & $0.5 \pm 3.0$ & $0.4 \pm 2.3$ \\
\hline PGAD & $5.4 \pm 3.5$ & $5.0 \pm 3-6$ & $0.4 \pm 1.2$ & $6.3 \pm 2.8(\mathbf{c})$ & $-0.9 \pm 2.7(\mathbf{d})$ & $5.1 \pm 3.2$ & $0.2 \pm 3.1$ & $4.6 \pm 2.7$ & $0.7 \pm 2.9$ \\
\hline
\end{tabular}

(1) to (7) indicate significant differences in delta values of within-group differences. (1) $=\mathrm{p}<0.063 ;$ (2) $=\mathrm{p}<0.063 ;(3)=\mathrm{p}<0.020 ;$ (4) $=\mathrm{p}<0.031 ;(5)=\mathrm{p}<$ $0.016 ;(6)=p<0.031 ;(7)=p<0.057$. (a) to (d) indicate significant differences in comparisons of corresponding data from the group A versus group B. (a) $=p$ $<0.035 ;$ (b) $=\mathrm{p}<0.027 ;$ (c) $=\mathrm{p}<0.032 ;(\mathrm{d})=\mathrm{p}<0.021$.

\subsection{Stiffness and Patients' Global Assessment of Disease Severity Are Reduced with RHP Treatment}

When stiffness of the dominant hand was evaluated using the average score for the individual activities in the pooled active and placebo treatments from the A and B groups, stiffness significantly declined after 3 weeks of active treatment $(p<0.020)$, but failed to attain statistical significance in comparison with placebo treatment, during testing after three months $(p<0.219)$. By contrast, no significant changes occurred at anytime in the placebo group (Table 2). If the 16 different activities were evaluated one by one, peeling potatoes came out as the activity with the most pronounced improvement. After 3 weeks of active treatment, there was a $23 \%$ reduction in stiffness $(\mathrm{p}<0.037)$ and a $25 \%$ reduction after 3 month $(\mathrm{p}<$ $0.022)$; as compared to initial levels. If the study groups were once more considered as groups A (active treatment first, then placebo) and B (placebo first, then active treatment), a significant difference between groups occurred after 3 weeks treatment in Phase $1(\mathrm{p}<0.027)$, see Table 3. However, this value did not attain statistical significance $(\mathrm{p}<0.192)$ after 3 months treatment.

The observations of reductions in pain and stiffness were strongly supported by the estimation of overall feeling of discomfort from the disease, based on self-assessments made by the study participants in the patients' global assessment of disease severity (PGAD). For example, when the A and B groups were lumped together, RHP 
treatment resulted in a borderline significant reduction in the feeling of discomfort after 3 months treatment $(\mathrm{p}<$ 0.091), Table 2. Again if the groups were split up into the groups $\mathrm{A}$ and $\mathrm{B}$, there was a significant difference between groups in PGAD with scores taken after the first three months of treatment $(p<0.021)$, Table 3. Here too, the positive impression on overall feeling was still present after 3 weeks on placebo.

\subsection{Rescue Medication and C-Reactive Protein Are Reduced with RHP Treatment}

Although no change was reported in the consumption of NSAIDs during the course of the study, overall consumption of other types of rescue medication fell significantly during active RHP treatment. For simplicity, Codeine and Tramadol consumed were converted into paracetamol units. The consumption of rescue medication during the first 14 days before RHP or placebo treatment with rescue medication taken during the last 14 days of Phase 1 of the study period is presented in Figure 2. Active treatment resulted in a decline in the number of paracetamol tablets consumed from $52.1 \pm 59.8$ to $34.7 \pm 57.5$ units, a $33 \%$ decline of $17.3 \pm 23.4$ units $(\mathrm{p}<0.007)$.

This decline should be compared to a modest increase in rescue medicine consumption observed during placebo treatment (Figure 2). Comparison of the decline or difference between initial and final medicine consumption in the two study groups yielded a p value of 0.013 .

The inflammatory marker, C-reactive protein was only

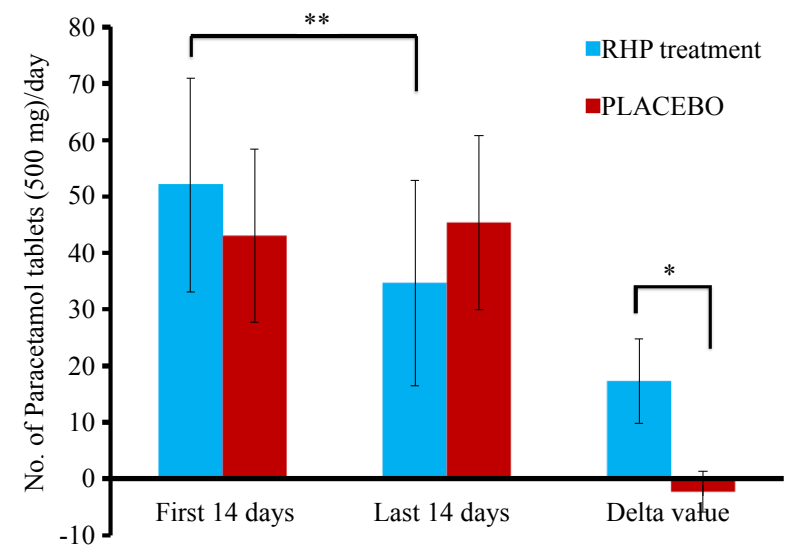

Figure 2. Comparisons of rescue medications taken by the study participants. Data are presented as mean value \pm SEM. Significant difference in the amount of rescue medication taken within the first 14 days as compared to that consumed in the last 14 days of Phase 1 of the study period in group $A$ (undergoing active RHP treatment) is expressed as $* * \mathbf{p}=0.007$. The reduction (following RHP treatment) and slight increase (with placebo) in rescue medication taken by the study subjects after Phase 1 are expressed as Delta values. (*p $=0.013$ comparing delta values of RHP and placebo.) detectible in eight patients, with using our routine laboratory methodology. Although the pre-treatment values fell significantly after active treatment $(p<0.047)$, there were no statistically significant differences between placebo and active treatment $(\mathrm{p}<0.120)$, Table 2 .

\subsection{Routine Screening Tests and Unwanted Side-Effects}

Haemoglobin, blood glucose, creatinine, sodium and potassium levels were unaffected by either active treatment or placebo (data not given). No patient dropped out during the study period due to unwanted side-effects and only mild side effects occurred. For example, one patient reported increased diuresis, while another reported developing a rash during active treatment. A third experienced diarrhoea during both treatment periods.

\subsection{Compliance}

Compliance was calculated from the proportion of investigational medicines returned by the patients. Compliance was $90.9+/-7.9$ for group A and $93.8+/-10.2$ for group $\mathrm{B}$, Mann-Whitney $\mathrm{p}$ value $=0.570$.

\section{Discussion}

The main outcome of this study is that chronic administration of the standardized RHP reduces pain and stiffness experienced during manual activity in patients with OA of the dominant hand. Nine out of ten patients reported reduction in pain while on the active treatment as compared to a modest $36 \%$ who reported pain reduction while on placebo $(\mathrm{p}<0.029)$. In addition, there was a statistically significant $33 \%$ reduction in the consumption of rescue medication while on active treatment. As the positive effects of pain reduction with RHP treatment were still indicated 3 weeks after the study participants were switched to placebo, the study also suggested a certain element of carry-over effect. Carry-over effect, if present is not an intrinsic disadvantage, since it simply implies a longer action of the drug than anticipated, but it constitutes a nuisance for interpretation of the results.

To the best of our knowledge, there are no other reports of placebo-controlled clinical trial of herbal remedies focusing on patients suffering from osteoarthritis of the hand, unlike the knee joints, which have been treated with ginger and avocado/soybean extracts $[21,22]$, or the hip and knee joints which have been treated with rose-hip [2-4]. Our results from testing the RHP for treatment of osteoarthritis of the hand agree well with previous reports, that administration of rose hip was effective in reducing pain in the hip and knee of patients with osteoarthritis severe enough for them to be put on the waiting list for hip or knee replacements [3]. This positive effect 
of the preparation on arthritis in other parts of the body suggests that rosehip influence may be systemic. Interestingly, our findings are supported by a metaanalysis of the present rose-hip product in which it was shown that the product had an effect size of reducing pain in patients with osteoarthritis, which was three times greater than paracetamol and better than glucosamine [23].

Rose hip preparations have been shown to have antiinflammatory activity $[14,15]$. Thus, the lessening of pain and stiffness observed in this study could come from the anti-inflammatory properties in the RHP. This idea has been given a powerful boost by the isolation of a certain galactolipid named GOPO, from the tested RHP, which had substantial anti-inflammatory activity, as defined by a reduction in neutrophil chemotaxis, even at low concentrations [16]. Lately, it was further demonstrated that the RHP and more profoundly, the newly isolated galactolipid GOPO exerted protection of human cartilage, by down regulating catabolic gene expression and up-regulating genes responsible for the synthesis of collagen in cells of human cartilage [17]. If the anti-inflammatory theory be true, the C-reactive protein level would be expected to fall as a result of RHP treatment. This proved to be so in the rather few patients where the CRP blood levels could be determined $(n=8)$ using our routine laboratory procedure. The fact that placebo treatment ended up in an intermediate position not significantly different from pre-treatment and active treatment might be explained from a certain carry over effect which was demonstrated in the relief of pain and stiffness, as well as in improvements in the overall feeling of discomfort. However, the CRP results should be taken with some precaution, as so few patients were involved.

It is widely known that rose hips contain quite large amounts of vitamin $\mathrm{C}$ and this is also true of the RHP preparation used in this study. However, it is highly unlikely that vitamin $\mathrm{C}$ accounts for much, or indeed any, of the efficacies associated with RHP against osteoarthritis in this study. For, a large-scale study in 1996 on the Framingham population group showed that a mean of 81 $\mathrm{mg}$ vitamin $\mathrm{C}$ daily intake for men and administration of similar levels for women did not protect against the development of osteoarthritis [24]. The content of natural vitamin $\mathrm{C}$ in the present daily Hyben Vital dosage is approximately $36 \mathrm{mg}$, i.e. only about one-third of the levels used in the aforementioned study.

It seems therefore more likely, that the beneficial impact of RHP on osteoarthritis of the dominant hand reported here is related to the anti-inflammatory and chondroprotective action of the preparation. This hypothesis may also explain why the effect appears to be systemic and takes some time before the efficacy is experienced. Also the impact from polyunsaturated fatty acids espe- cially present in the seeds of rose hip can account for some of the disease symptoms reduction observed in this study [25]. By comparison, true painkillers, like the NSAIDs, paracetamol, Codeine and Tramadol relieve pain within a few hours of administration. Thus, while this RHP was reported to alleviate pain due to OA of the knee and hip after administration for a period of 3 weeks, we found that 3 month administration was required to significantly ease the symptoms of OA of the hand.

\section{Conclusion}

The rose hip preparation of the subspecies Rosa canina used in this study can alleviate joint pain and stiffness in patients with osteoarthritis of the dominant hand. The efficacy was strong enough to reduce the patients' feeling of discomfort from the disease. We consider that the results warrant a large-scale, parallel study of the RHP in patients with osteoarthritis of the hand. It is also important to note that the consumption of rescue medication was considerably reduced as a result of RHP treatment. The fact that patients were allowed to reduce their consumption of rescue medication, and did so, may have blunted some further impact on symptom scores from RHP, but would have left us without the knowledge, that RHP treatment was strong enough to change the consumption of rescue medication. Future research should also include a comparison of different Rose-hip products, as their content of the implicated anti-inflammatory ingredients and way of production can vary considerably, thereby making it difficult to predict its real the impact on reducing the symptoms of $\mathrm{OA}$.

\section{Acknowledgements}

We are thankful to HybenVital International, Langeland, Denmark, who kindly provided the placebo and RHP capsules. Thanks to Britta Johnsen and Alis Milman for help with preparation of the manuscript and for excellent technical assistance.

\section{REFERENCES}

[1] M. Blumenthal, W. R. Busse, A. Goldberg, J. Gruenwald, T. Hall, S. Klein, C. W. Riggins and R. S. Rister, "The Complete German Commission E Monographs, Therapeutic Guide to Herbal Medicines," American Botanical Council, Boston, 1998.

[2] E. Rein, A. Kharazmi and K. Winther, "A Herbal Remedy, Hyben Vital (stand. Powder of Rosa canina Fruits), Reduces Pain and Improves General Wellbeing in Patients with Osteoarthritis-A Double-Blind, Placebo-Controlled, Randomised Trial," Phytomedicine, Vol. 11, No. 5, 2004, pp. 383-391. doi:10.1016/j.phymed.2004.01.001

[3] O. Warholm, S. Skaar, E. Hedman, H. M. Mølmen and L. 
Eik, "The Effect of a Standardized Herbal Remedy Made from a Subtype of Rosa canina in Patients with Osteoarthritis: A Double-Blind, Randomized, Placebo-Controlled Clinical Trial," Current Therapeutic Research, Vol. 64, No. 1, 2003, pp. 21-31. doi:10.1016/S0011-393X(03)00004-3

[4] K. Winther, K. Apel and G. A. Thamsborg, "A Powder Made from Seeds and Shells of a Rose Hip Subspecies (Rosa canina) Reduces Symptoms of Knee and Hip Osteoarthritis: A Randomized, Double-Blind, Placebo-Controlled Clinical Trial," Scandinavian Journal of Rheumatology, Vol. 34, No. 4, 2005, pp. 302-308. doi:10.1080/03009740510018624

[5] S. N. Willich, K. Rossnagel, S. Roll, A. Wagner, O. Mune, J. Erlendson, A. Kharazmi, H. Sørensen and K. Winther, "Rose Hip Herbal Remedy in Patients with Rheumatoid Arthritis-A Randomized Controlled Trial," Phytomedicine, Vol. 17, No. 2, 2010, pp. 87-93. doi:10.1016/j.phymed.2009.09.003

[6] E. Harris Jr., "Pathogenesis of Rheumatoid Arthritis: A Disorder Associated with Dysfunctional Immunoregulation,” In: J. H. Gallin, I. M. Goldstein and R. Snyderman, Eds., Inflammation. Basic Principles and Clinical Correlates, Raven Press, New York, 1988, pp. 751-773.

[7] M. C. Hochberg, R. D. Altman, K. D. Brandt, B. M. Clark, P. A. Dieppe, M. R. Griffin, W. Moskowitz and T. J. Schnitzer, "Guidelines for the Medical Management of Osteoarthritis (Parts 1 and 2)," Arthritis \& Rheumatism, Vol. 38, 1995, pp. 1533-1546.

[8] J. R. Vane and R. M. Botting, "Anti-Inflammatory Drugs and Their Mechanisms of Action," Inflammatory Research, Vol. 47, 1998, pp. 578-587.

[9] M. R. Griffin, J. M. Piper, J. R. Daugherty, M. Snowden and W. A. Ray, "Nonsterioidal Anti-Inflammatory Drug Use and Increased Risk for Peptic Ulcer Disease in Elderly Persons," Annals of Internal Medicine, Vol. 114, 1991, pp. 257-263. doi:10.7326/0003-4819-114-4-257

[10] D. Mukherjee, S. E. Nissen and E. J. Topol, "Risk of Cardiovascular Events Associated with Selective Cox-2 Inhibitors," Journal of the American Medical Association, Vol. 286, No. 8, 2001, pp. 954-959. doi:10.1001/jama.286.8.954

[11] F. E. Silverstein, G. Faich, J. L. Goldstein, L. S. Simon, T. Pincus, A. Whelton, R. Makuch, G. Eisen, N. M. Agrawal, W. F. Stenson, A. M. Burr, W. W. Zhao, J. D. Kent, J. B. Lefkowith, K. M. Verburg and G. S. Geis, "Gastrointestinal Toxicity with Celecoxib vs Nonsteroidal Anti-inflammatory Drugs for Osteoarthritis and Rheumatoid Arthritis. The CLASS Study: A Randomized Controlled Trial," Journal of the American Medical Association, Vol. 284, 2000, pp. 1247-1255. doi:10.1001/jama.284.10.1247

[12] G. H. Gislason, S. Jacobsen, J. N. Rasmussen, S. Rasmussen, P. Buch, J. Friberg, T. K. Schramm, S. Z. Abildstrom, L. Køber, M. Madsen and C. Torp-Pedersen, "Risk of Death or Reinfarction Associated with the Use of Selective Cyclooxygenase-2 Inhibitors and Nonselective Nonsteroidal Anti-Inflammatory Drugs after Acute Myocardial Infarction," Circulation, Vol. 27, 2006, pp. 2906-

\section{3. doi:10.1161/CIRCULATIONAHA.106.616219}

[13] L. A. C. Rodrigues and S. Hernandes-Diaz, "Relative Risk of Upper Gastrointestinal Complications among Users of Acetaminophen and Non-steroidal Anti-inflammatory Drugs," Epidemiology, Vol. 12, No. 5, 2001, pp. 570-576. doi:10.1097/00001648-200109000-00018

[14] K. Winther, E. Rein and A. Kharazmi, "The Anti-Inflammatory Properties of Rose Hip," Inflammopharmacology, Vol. 7, No. 1, 1999, pp. 63-68. doi:10.1007/s10787-999-0026-8

[15] A. Kharazmi and K. Winther, "Rose-Hip Inhibits Chemotaxis and Chemiluminescence of Human Blood Neutrophils in Vitro and Reduces Certain Inflammatory Parameters in Vivo," Inflammopharmacology, Vol. 7, No. 4, 1999, pp. 377-386. doi:10.1007/s10787-999-0031-y

[16] E. Larsen, A. Kharazmi, L. P. Christensen and S. B. Christensen, "An Anti-Inflammatory Galactolipid from Rose Hip (Rosa canina L.) That Inhibits Chemotaxis of Human Peripheral Blood Neutrophils in Vitro," Journal of Natural Products, Vol. 66, 2003, pp. 994-995. doi:10.1021/np0300636

[17] J. Schwager, U. Hoeller, S. Wolfram and N. Richard, "Rose Hip and Its Constituent Galactolipids Confer Cartilage Protection by Modulating Cytokine and Chemokine Expression," BMC Complementary and Alternative Medicine, Vol. 11, 2011, p. 105. doi:10.1186/1472-6882-11-105

[18] R. Altman, G. Alarcon, D. Appelrouth, D. Bloch, D. Borenstein, K. Brandt, et al., "The American College of Rheumatology Criteria for the Classification and Reporting of Osteoarthritis of the Hand," Arthritis and Rheumatism, Vol. 33, No. 11, 1990, pp. 1601-1610. doi:10.1002/art.1780331101

[19] L. Recht, T. Lithman, J. O. Rasmussen and F. K. Mathiesen, "Self-Test for Detection of Hand Dysfunction in Population Studies," Practitioner, Vol. 232, 1988, pp. 1236-1239.

[20] K. Eberhardt, L. Recht, T. Lithman, B. Schersten, F. Wollheim and H. Petterson, "Detection of Suspected Inflammatory Joint Disease with a New Self-administered Hand Test," British Journal of Rheumatology, Vol. 27, 1988, pp. 457-461. doi:10.1093/rheumatology/27.6.457

[21] R. D. Altman and K. C. Marcussen, "Effect of a Ginger Extract on Knee Pain in Patients with Osteoarthrosis," Arthritis and Rheumatism, Vol. 44, 2001, pp. 2531-2538. doi:10.1002/1529-0131(200111)44:11<2531::AID-ART4 $33>3.0 . \mathrm{CO} ; 2-\mathrm{J}$

[22] T. Appelboom, J. Schuermans, G. Verbruggen, Y. Henrotin and J. Y. Reginster, "Symptoms Modifying Effect of Avocado/Soybean Unsaponifiables (ASU) in Knee Osteoarthritis," Scandinavian Journal of Rheumatology, Vol. 30, No. 4, 2001, pp. 242-247. doi:10.1080/030097401316909602

[23] R. Christensen, E. M. Bartels, R. D. Altman, A. Astrup and H. Bliddal, "Does the Hip Powder of Rosa canina (Rosehip) Reduce Pain in Osteoarthritis Patients? A MetaAnalysis of Randomized Controlled Trials," Osteoarthritis and Cartilage, Vol. 16, No. 9, 2008, pp. 965-972. 
doi:10.1016/j.joca.2008.03.001

[24] T. E. McAlindon, P. Jacques, Y. Zhang, M. T. Hannan, P. Aliabadi, B. Weissman, D. Rush, D. Levy and D. T Felson, "Do Antioxidant Micronutrients Protect against the Development and Progression of Knee Osteoarthritis?" Arthritis and Rheumatism, Vol. 39, No. 4, 1996, pp. 648-
656. doi:10.1002/art.1780390417

[25] L. J. Leventhal, E. G. Boyce and R. B. Zurier, "Treatment of Rheumatoid Arthritis with Gammalinolenic Acid," Annals of Internal Medicine, Vol. 119, No. 9, 1993, pp. 867-873.

doi:10.7326/0003-4819-119-9-199311010-00001 